CCDS provides both oral health promotion and clinical dentistry. Just like many other aspects to delivering a clinical dental service, these include: running the reception and waiting area, assisting in the decontamination room, re-stocking of mobile units, providing outreach triage for guests attending one of the other Crisis at Christmas sites and making cups of tea for guests and volunteers. This year we even had a dental laboratory set up on site to make same-day dentures. There is always something to keep our volunteers busy and that might also include spending time helping to make our guests feel welcome by chatting and playing board games with them while they wait for their appointment.

\section{Q. Why do you continue to do it?}

\section{CCDS provides such an amazing}

service; every year we deliver dental care to over 400 people experiencing homelessness, some $75 \%$ of whom do not access another dentist throughout the year. We help to get people out of pain so they can enjoy their Christmas dinner, we chat and laugh and enjoy music and games with the guests, we use both our clinical and nonclinical skills to do real good. When dental professionals from across the country come to volunteer at Crisis at Christmas they arrive as strangers, they spend their shift working as colleagues and they leave as friends. Though it is not without its challenges, I have thoroughly enjoyed every year I've volunteered and I couldn't imagine a Christmas without Crisis now.

\section{Q. Any reaction from your family?}

The first year I volunteered for CCDS my mum was a little sad to see me leave for London on Boxing Day. However; Crisis at Christmas has now become a regular feature in our festivities and we still get plenty of time to spend together as a family. And what does my partner think? Well, he and I met at CCDS and we continue to volunteer together every year!

bdjteam2018206

\title{
Filling the void
}

- a dental lab service for the homeless

\section{Dental technician Andrea Johnson}

\section{describes the work of Den-Tech, the charity she co-founded.}

I set up Den-Tech in 2017 with Andrew Sinclair because we saw a void we could fill that would help to complete the circle of care given by other dental charities. We can restore the smile of the patient once pain-relieving treatment is completed.

We enlisted trustees and committee members chosen for their skills and expertise from all across the dental team, the additional trustees were Edward Mapley - a dental technology lecturer at Cardiff Metropolitan University, Jade Oakes a hospital based dental technician currently also studying her Max Fac qualification and Delroy Reeves a crown and bridge lab owner. The council of volunteers/advisors also includes clinician Sami Stagnell, CDT Rowland Gardner and dental nurse/oral health specialist Fiona Ellwood.

The Den-Tech team are passionate about helping out wherever they can and we have several projects running designed to help those most in need.

One of the projects was setting up and running a 'field laboratory' alongside the Crisis at Christmas Dental Service. In 2017 the first pilot laboratory was set up and we made 24 same day dentures for the homeless guests residing in the Crisis centres.

There were many challenges due to the fact that the area the allocated space in is not designed to accommodate a dental laboratory and the subsequent waste it can produce. We couldn't, for example, allow plaster waste or molten wax to go down the sinks and into the waste pipes and we couldn't therefore have a model grinder; if you can't grind up the model bases you can't articulate them which caused another issue! We also had problems with the time it took for the plaster to set causing slight delays in the turnaround times.

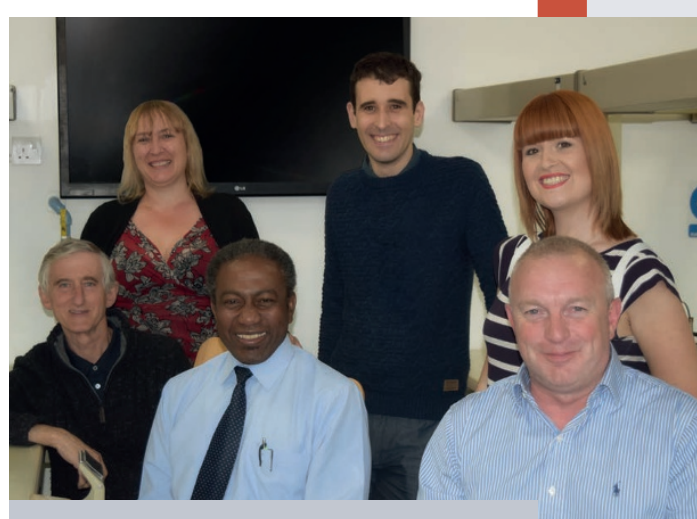

Back (I-r) Andrea Johnson, Edward Mapley and Jade Oakes and front (I-R) Robert Williams, Delroy Reeves and Andrew Sinclair.

Despite the challenges, myself and the team of technician volunteers threw ourselves into the work for the sake of the patient. Though I say it myself, we produced some great work with very limited resources. Every guest collected their appliance and was happy with the result.

To be able to offer this type of service is incredibly rewarding and Den-Tech have made a commitment to the Crisis at Christmas Dental Service to support their work and will make great strides forwards with the lessons learned each year.

Den-Tech feel proud \& honoured to be able to help restore the smiles, confidence and dignity of some of the most vulnerable members of society and welcome anyone who wishes to sign up and help out for what we are sure will be an even busier year, but just as rewarding.

For more information, email me at dentech.chair@gmail.com or to sign up for the Den-Tech/Crisis@Cristmas volunteering please go to: https://www. crisis.org.uk/get-involved/christmasvolunteering-london/

bdjteam2018207 